\title{
DOS NOTITAS SOBRE LOPE DE VEGA
}

I. Osorio el de los cuartos

Se trata de unas alusiones que voy a especificar en seguida. Ya Thornton Wilder se había fijado en ellas ( $R P h, 7,1953-54$, p. 24), pero nadie hasta ahora ha logrado hallar el origen de esta historia. Con la esperanza de que algún lector pueda dar con él, transcribo aquí los trozos pertinentes.

1. Galindo-iHa, pobre seso echizado!

Mas que ha de darse el cuitado

como los cuartos de Osorio.

Lope de Vega, La prueba de los amigos (1604), ed. Simpson, Madrid, 1934, vs. 1964-66.

2. Don LOPE-Te suplico por Él [Dios] que si delante vieses de ti, mientras el fin te digo,

las sombras que vio Osorio el estudiante, no despliegues los labios.

DON VASCO-

Primo amigo,

hermano, ¡vive Dios!, de estar a todo como una piedra, y que a callar me obligo si viese descender del propio modo

los cuartos de aquel hombre a media noche.

Lope de Vega, Los Porceles de Murcia (i16041608?), Acad, t. II, p. $579^{a b}$.

3. Lisardo-De aquel Osorio habréis la historia oído que vio caer el hombre cuarto a cuarto: lo mismo a mi temor le ha sucedido, con que de amor el pensamiento aparto.

Lope de Vega, Quien ama no haga fieros (¿16201622?), AcadN, t. 19, p. $43^{1}$.

4. Decís bien, $y$ aun es notorio por nombres averiguados de vuestro antiguo abolorio, que os viene por dos costados el ser Costilla y Osorio.

Luis Martín de la Plaza, "A una mujer flaca", en 
Cancionero antequerano $[1627-1628]$, ed. D. Alonso y R. Ferreres, Madrid, $195^{\circ}$, p. $234^{1}$.

5 .

Los cuartos de los Osorios eran los de la Quincoces, que se le andaban cayendo a lo títere de goznes.

Quevedo, romance "Sepan cuantos, sepan cuantas", $B A E$, t. 69 , p. $160 a^{2}$.

Se ve, pues, que entre los años de ${ }_{1} 60_{4}$ y ${ }_{1} 6$ go corría una historieta tan conocida de todo el mundo que no necesitaba explicaciones. El público teatral y los lectores de poesía lírica captaban la alusión sin dificultad alguna. Pero a nosotros, lectores de una edad posterior, se nos oculta. No era una mujer desnuda la que bajaba por la escalera, sino un cuerpo deshecho en cuartos, y un estudiante nombrado Osorio vio este fantasma y se espeluznó (iy vaya que los estudiantes no se asustan con facilidad!).

¿Tendrá algún erudito muy versado en novelas picarescas la fortuna de dar con el original? ¿O se halla oculto en las crónicas de la época, en Cabrera de Córdoba, en Contarini, o en algún otro diarista?

\section{LOPE Y LAS UNIDADES DRAMÁTICAS}

Bastante se han discutido las ideas que Lope expresó en su célebre Arte nuevo de hacer comedias ${ }^{3}$. No pienso volver sobre lo ya escrito, sino añadir unas cuantas observaciones, posiblemente nuevas.

Ante todo, cabe observar que de las tres unidades, de acción, de tiempo y de lugar (que no deben llamarse aristotélicas, sino italianas), Lope solamente menciona las dos primeras. De la de lugar nunca dice nada, que sepamos (en esto concuerda con Aristóteles). De la de acción sí habla (vs. 181-187):

Adviértase que solo este sujeto tenga una acción, mirando que la fábula de ninguna manera sea episódica, quiero dezir inserta de otras cosas

1 Debo esta cita y la siguiente a mi amigo y colega el profesor Edwin $S$. Morby.

2 La primera edición de Quevedo es de ${ }^{6} 648$. En la ed. de Astrana Marín, Obras en verso, $193^{2}$, p. $53^{8}$, lleva esta poesía la fecha "¿1625?", no sé por qué motivo.

3 Véanse sobre todo A. Morel-Fatio, "L'Arte nuevo de hazer comedias en este tiempo de Lope de Vega", $B H i, 3$ (1901), 365-405; ID., "Les défenseurs de la comedia", BHi, 4 (1902), 30-62; H. J. CHAYTOR, Dramatic theory in Spain, Cambridge University Press, 1925; M. Romera Navarro, "Lope de Vega y las unidades dramáticas", $H R, 3$ (1935), 190-201. 
que del primero intento se desvíen, ni que della se pueda quitar miembro que del contexto no derribe el todo.

Raras veces obedece Lope en la práctica este concepto tan puramente aristotélico. En cuanto a la unidad de tiempo, su actitud es resueltamente rebelde (vs. 188-19o):

No ay que advertir que passe en el período de un sol, aunque es consejo de Aristóteles, porque ya le perdimos el respeto...

Antes había escrito los conocidos versos $\left(33^{-3} 8\right)$ :

Verdad es que yo he escrito algunas veces siguiendo el arte que conocen pocos, mas, luego que salir por otra parte veo los monstruos, de apariencia llenos, adonde acude el vulgo y las mugeres que este triste exercicio canonizan...

(¿Quién no piensa en la televisión de hoy día?). Y al final (vs. 367$371)$ repite:

Pero ¿qué puedo hazer, si tengo escritas con una, que he acabado esta semana, quatrocientas y ochenta y tres Comedias? Porque, fuera de seis, las demás todas pecaron contra el arte gravemente.

Estos versos se publicaron en 1609 , cuando tenía el poeta 47 años. Del número de comedias, de la desbordada invención del dramaturgo, hemos tratado en otro sitio ${ }^{4}$. Nunca debemos fiarnos totalmente de las declaraciones de Lope; se deleitaba en despistar al lector. Pero es cierto que había escrito muchas más comedias que ningún otro dramaturgo de su época o de cualquier otra.

Si quisiéramos, pues, descubrir entre tantos dramas los seis escritos con arte, emprenderíamos una tarea casi imposible. En primer lugar, hay que suponer que seis no es sino un número indefinido, lo mismo que algunas. Y confieso que no he examinado desde el punto de vista de las unidades todas las comedias existentes escritas antes de 1609, que serán unas doscientas. Ticknor decía: "En cuanto a las seis que, según él asegura, escribió ajustándose enteramente a las reglas del teatro griego, los críticos españoles las han buscado hasta ahora en vano, y es probable que ninguna de ellas exista, a no ser

4. S. G. Morley y Courtney Bruerton, "How many comedias did Lope de Vega write?", $H, 19(1936), 217-234$. 
una, La melindrosa"5. Un hispanófilo alemán se atrevió a nombrar tres comedias que podrían, según él, pertenecer a las seis en cuestión ${ }^{6}$ : Amor con vista, La ilustre fregona y Lo que pasa en una tarde (que Hennigs no leyó).

Tuvo mala suerte el doctor Hennigs en sus conjeturas. No podía disponer de los conocimientos que poseemos nosotros. Hoy sabemos que Lo que pasa en una tarde se escribió en 1617 (ms. autógrafo), y que Amor con vista es de 1626 (ms. autógrafo); así estas comedias no entraban en los cálculos lopescos de 16og. La ilustre fregona, en el texto que tenemos, mal pudo ser escrita por Lope de $V e^{7}{ }^{7}$. De manera que las seis comedias, si existen, tienen que ser otras.

Saltemos ahora doce años hasta 1621. En el "Prólogo dialogístico" a la Parte XVI (Madrid, 1621) pregunta El Forastero: "¿Son buenas estas comedias?", y contesta El Teatro: "Mirad a quien alabáis, El Perseo, El Laberinto, y Los prados, El Adonis y Felisarda están de suerte escritas, que parece que se detuvo [Lope] en ellas"8. Otra vez seis comedias; pero ¿en qué sentido se jacta Lope de haber producido obras esmeradas? Ciertamente no por haber respetado las Reglas. Las que tratan temas mitológicos (El Perseo, El Laberinto de Creta y Adonis y Venus) están muy lejos de las unidades de lugar, de tiempo o de acción; Los prados de León tiene cierto interés, pero no es por obedecer a ninguna unidad; Mirad a quien alabáis exhibe la imaginación del autor hasta el punto de dejar confuso al lector; aún más estrafalaria es La Felisarda. Se ve, pues, que cuando Lope dijo que "se detuvo" en escribir estas comedias aludía al estilo poético, a la riqueza del sentimiento lírico, y no a la regularidad de la acción, ni a lo lógico de la psicología de los personajes.

Sin embargo, Lope escribió algunas comedias - que no alabacuya acción se desarrolla en un solo día. Tales son, en orden cronológico, El mesón de la corte (1588-95), Las ferias de Madrid (antes de 1596), La noche toledana (1605), Los melindres de Belisa (La

5 Ticknor, Historia de la literatura española, trad. Gayangos y Vedía, t. 2, Madrid, $185^{1}$, p. $3^{8} 3$.

6 Wilhelm Hennigs, Studien zu Lope de Vega Carpio. Eine Klassifikation seiner Comedias, Göttingen, 189ı, pp. 59-68.

7 Morley-Bruerton, The chronology of Lope de Vega's "comedias", New York, 1949, passim, en especial pp. 44, 47, 293-294. En cuanto a las características de estas tres comedias, todas son de acción rápida y de lugar más o menos estacionario. Lo que pasa en una tarde, en efecto, ocupa sólo una tarde; la escena es en Madrid, unas veces en una casa particular y otras en la Casa del Campo (parque público). Amor con vista se sitúa en Nápoles, en una calle; la acción ocupa dos días y una noche. La ilustre fregona se desarrolla en un mesón de Toledo y ofrece una acción casi continua.

$8 B A E$, t. 52, p. xxvia. Dos de estos títulos pueden ser anteriores a 1609 : Los prados y El Adonis. 
melindrosa de Ticknor, 16o6-o8), Lo que pasa en una tarde (1617), La noche de San Juan (1631), y puede haber otras que no conozco. El lugar cambia poco, como era de suponer en tan pequeño espacio de tiempo.

¿Hemos de presumir que Lope quería demostrar en estas piezas su capacidad de amoldarse a las Reglas que conocía tan a fondo, y a las cuales no deseaba ni necesitaba obedecer? Ello no es creíble ${ }^{9}$. Cuando, en la infinita variedad de su desbordante imaginación, daba con una idea, con una trama que pedía una acción rapidísima, la desarrollaba conforme a la naturaleza de la situación. Así, sin quererlo, demostró que las unidades cuasi-aristotélicas no son necesariamente grilletes ni impedimentos, sino que condensan y refuerzan el poder de una acción cuando ésta posee la intensidad idónea. Es una verdad muchas veces olvidada por los críticos, pero que conocen muy bien los dramaturgos modernos de más éxito. Para probarlo, he aquí una lista parcial de obras teatrales de los siglos XIX $\mathrm{y} \mathrm{xx}$ que se ajustan estrictamente a las unidades de tiempo (24 horas) y de lugar (una sola escena): Ibsen, Los espectros, Casa de muñecas; Strindberg, El padre, La señorita Julia; Enrique Gaspar, Huelga de hijos, La eterna cuestion; Hecht y MacArthur, The front page; Elmer Rice, Street scene; Saroyan, The beautiful people; J. B. Priestley, Dangerous corner; Eugene O'Neill, A touch of the poet. Estos autores seguramente no se consideraban atados por regla alguna clásica; miraban tan sólo al mayor efecto dramático de sus composiciones.

S. Griswold Morley

University of California.

9 Sin embargo, era consciente de lo que hacía. Los versos finales de La noche de San Juan $(A c a d N$, t. 8, p. 166b) rezan así:

Aquí la comedia acaba de la noche de San Juan; que si el arte se dilata a darle por sus preceptos al poeta, de distancia, por favor, veinte y cuatro horas, ésta en menos de diez pasa. 